\title{
Ambulatory anesthesia for patients with sleep apnea
}

This article was published in the following Dove Press journal:

Ambulatory Anesthesia

3 December 2015

Number of times this article has been viewed

\author{
Raviraj Raveendran' \\ Frances Chung ${ }^{2}$ \\ 'West Coast District Health Board, \\ Department of Anesthesiology, \\ Greymouth, New Zealand; \\ ${ }^{2}$ Department of Anesthesiology, \\ Toronto Western Hospital, University \\ Health Network, University of \\ Toronto, Toronto, ON, Canada
}

\begin{abstract}
The prevalence of obstructive sleep apnea (OSA) is increasing, and a significant number of patients with OSA presenting for ambulatory surgeries are undiagnosed. It is well known that patients with OSA have increased postoperative complications. The suitability of ambulatory surgery in patients with OSA remains controversial, and the evidence regarding the safety of OSA patients for ambulatory surgery is inadequate. Anesthesiologists play an important role in identifying, evaluating, and optimizing the OSA patient. Preoperative screening and careful selection of patients for ambulatory surgery is the key step during the perioperative management of OSA patients. With proper screening and clinical algorithm-based management, patients with OSA may be treated safely as ambulatory surgical patients.

Keywords: obstructive sleep apnea, ambulatory surgery, perioperative management, postoperative complications
\end{abstract}

\section{Introduction}

Obstructive sleep apnea (OSA) syndrome is the most common type of sleep-disordered breathing, and is characterized by recurrent apnea and hypopnea lasting $\geq 10$ seconds during sleep. In patients with OSA, there is an increased depression of pharyngeal muscle tone during sleep and anesthesia, resulting in a recurrent pattern of partial or complete upper-airway obstruction with impaired respiration. ${ }^{1}$ The prevalence of mild OSA is one in four males and one in ten females; ${ }^{2,3}$ moderate OSA is one in nine males and one in 20 females. ${ }^{4,5}$ A significant number of OSA patients are undiagnosed when they come for elective surgery. ${ }^{6}$ Approximately $10 \%-20 \%$ of surgical patients, of whom $80 \%$ had not been previously diagnosed with OSA, have been found to be at high risk of OSA based on preoperative screening. ${ }^{7,8}$ An increase in the prevalence of OSA as well as an increase in surgeries performed as ambulatory procedures poses a practical challenge to the anesthesiologist. OSA is associated with multiple comorbidities, and the suitability of ambulatory surgery in OSA patients remains controversial, due to the concerns of increased perioperative complications, including postdischarge death. At present, the evidence related to the safety of OSA patients for ambulatory surgery is limited. The American Society of Anesthesiologists (ASA), ${ }^{9,10}$ and Society for Ambulatory Anesthesia (SAMBA) ${ }^{11}$ have published guidelines to emphasize the importance of proper patient selection and management of OSA patients for ambulatory surgery.

\section{Risk factors and pathophysiology}

OSA is predisposed by various pathophysiological, demographic, and lifestyle factors. These include anatomical abnormalities that may cause mechanical changes in the 
airway lumen (eg, craniofacial deformities, retrognathia, macroglossia), connective tissue diseases (eg, Marfan's syndrome), endocrine diseases (eg, hypothyroidism, Cushing's disease), male sex, neck circumference $>40 \mathrm{~cm}$, age above 50 years, and lifestyle factors, including alcohol consumption and smoking. ${ }^{12}$ The prevalence of OSA may be higher - up to $78 \%$ - in morbidly obese patients scheduled for bariatric surgery. ${ }^{13}$ Obesity causes enlargement of soft-tissue structures around the airway, causing pharyngeal airway narrowing. Lung volumes are markedly reduced by increase in the abdominal fat mass. Reduction of lung volume may decrease longitudinal tracheal traction forces and pharyngeal wall tension, which causes narrowing of the airway. Visceral obesity is common in subjects with OSA. ${ }^{14}$ OSA is associated with various comorbidities, such as myocardial ischemia, heart failure, hypertension, arrhythmias, metabolic syndrome, cerebrovascular disease, insulin resistance, gastroesophageal reflux, and obesity. Sympathetic activation is increased by apneic episodes, which prevents the normal nocturnal decline in blood pressure. Sleep apnea associated with obesity leads to increased sympathetic tone, hypertension, left ventricular hypertrophy, chronic hypoxemia, and exaggerated swings in intrathoracic pressure during obstructive episodes. OSA also causes an increase in right ventricular cavity size and wall thickness. OSA is one of the common reasons for resistance hypertension. ${ }^{15}$ Though OSA is not a component of metabolic syndrome (central obesity, hypertension, hyperlipidemia, and insulin resistance), there is experimental and clinical evidence to show the relationship between OSA and cardiometabolic syndrome. ${ }^{16}$ Anesthetics agents, including sedative hypnotics, opioids, and muscle relaxants, exaggerate OSA-related airway instability and worsen the apnea. Surgical stress response during the postoperative period significantly changes the sleep architecture. ${ }^{17}$ This warrants a careful understanding of pathophysiology of OSA and the effects of anesthetic on the syndrome.

Obesity hypoventilation syndrome (OHS) is a condition with the triad of obesity, daytime hypoventilation, and sleepdisordered breathing without an alternative neuromuscular, mechanical, or metabolic cause of hypoventilation. It is a disease distinct from simple obesity and OSA. OHS is often undiagnosed, with a prevalence of $10 \%-20 \%$ in obese patients with OSA and $0.15 \%-0.3 \%$ among general adult population. Compared to eucapnic obese patients, OHS patients present with blunted central respiratory drive, severe upper-airway obstruction, restrictive chest physiology, pulmonary hypertension, and increased mortality.
Noninvasive positive airway pressure (PAP) is the mainstay of therapy. ${ }^{18}$

\section{Diagnostic criteria of OSA}

The gold standard for the diagnosis of OSA is polysomnography or sleep study. The Apnea-Hypopnea Index (AHI), defined as the average episode of abnormal breathing events per hour of sleep, is used to diagnose and assess the severity of OSA. An apneic event is cessation of airflow for 10 seconds, and hypopnea is reduced airflow with desaturation $\geq 4 \%$. Diagnostic criteria for OSA by the American Academy of Sleep Medicine require either an AHI $\geq 15$ or AHI $\geq 5$ with symptoms, such as daytime sleepiness, loud snoring, or observed obstruction during sleep. ${ }^{19}$ OSA severity is considered mild for $\mathrm{AHI} \geq 5-15$, moderate for AHI 15-30, and severe for $\mathrm{AHI}>30$.

\section{Methods for preoperative screening for OSA}

As screening with polysomnography is expensive and resource-intensive, many other screening tools have been developed. ${ }^{20}$ The SAMBA guidelines recommend using the STOP-Bang questionnaire as a first step, because it is simple to administer. The STOP-Bang questionnaire was initially developed in surgical patients, but has been validated in various patient populations (Table 1). ${ }^{21-23}$ Patients with a STOP-Bang score of 0-2 are considered low risk, 3-4 intermediate risk, and 5-8 high risk of OSA. The STOP-Bang questionnaire has the highest methodological validity and accuracy in predicting a diagnosis of OSA, ${ }^{20,24}$ and a STOPBang score of 5-8 identifies patients with a high possibility of moderate-to-severe OSA. ${ }^{22}$ The addition of a serum bicarbonate level $\geq 28 \mathrm{mmol} / \mathrm{L}$ to a STOP-Bang score $\geq 3$ increases the specificity for a preoperative diagnosis of OSA. ${ }^{25}$ For obese or morbidly obese patients, a STOP-Bang score of 4 or greater can be used as a cutoff. ${ }^{26}$ Patients with a higher STOP-Bang score are more likely to have increased postoperative complications. ${ }^{27}$

Also, the Oxygen Desaturation Index (ODI) from a high-resolution oximeter is sensitive and specific to identify undiagnosed sleep-disordered breathing in surgical patients. ${ }^{28}$ ODI is a good predictor of AHI. ODI $\geq 10$ demonstrates high sensitivity (93\%) and reasonable specificity (75\%) to detect moderate and severe OSA. Patients with preoperative mean overnight $\mathrm{SpO}_{2}<93 \%$, or ODI $>29$ events/hour were recently shown to be at higher risk for postoperative complications. ${ }^{29}$ These screening tests are not adequate to differentiate OSA from other sleep disorders, such as OHS 
Table I STOP-Bang questionnaire

\begin{tabular}{|c|c|c|}
\hline Yes & No & Snoring? \\
\hline O & O & $\begin{array}{l}\text { Do you snore loudly (loud enough to be heard } \\
\text { through closed doors or your bed partner elbows } \\
\text { you for snoring at night)? }\end{array}$ \\
\hline Yes & No & Tired? \\
\hline O & O & $\begin{array}{l}\text { Do you often feel tired, fatigued, or sleepy during the } \\
\text { daytime (such as falling asleep during driving)? }\end{array}$ \\
\hline Yes & No & Observed? \\
\hline O & O & $\begin{array}{l}\text { Has anyone observed you stop breathing or choking/ } \\
\text { gasping during your sleep? }\end{array}$ \\
\hline Yes & No & Pressure? \\
\hline O & $\mathrm{O}$ & $\begin{array}{l}\text { Do you have or are being treated for high blood } \\
\text { pressure? }\end{array}$ \\
\hline Yes & No & \\
\hline 0 & $\mathrm{O}$ & Body mass index more than $35 \mathrm{~kg} / \mathrm{m}^{2}$ ? \\
\hline Yes & No & \\
\hline \multirow[t]{2}{*}{ O } & O & Age older than $\mathbf{5 0}$ years? \\
\hline & & $\begin{array}{l}\text { Neck size large? (measured around Adam's } \\
\text { apple) }\end{array}$ \\
\hline Yes & No & For male, is your shirt collar 17 inches or larger? \\
\hline O & O & For female, is your shirt collar 16 inches or larger? \\
\hline Yes & No & \\
\hline 0 & $\mathrm{O}$ & Sex $=$ male? \\
\hline
\end{tabular}

Notes: Scoring criteria (for general population): low risk of OSA, yes to 0-2 questions; intermediate risk of OSA, yes to $3-4$ questions; high risk of OSA: yes to 5-8 questions, yes to 2 of 4 STOP questions + individual's sex is male, yes to 2 of 4 STOP questions + BMl $>35 \mathrm{~kg} / \mathrm{m}^{2}$, yes to 2 of 4 STOP questions + neck circumference (male) 17"/(female) 16". Property of University Health Network.

Abbreviations: OSA, obstructive sleep apnea; BMI, body mass index.

and central sleep apnea. If these are suspected, an arterial blood gas and an overnight polysomnography are indicated to diagnose hypercarbia and effortless apnea, respectively.

Studies suggest that patients with OSA who have been treated with CPAP preoperatively have fewer perioperative complications than those untreated. ${ }^{30}$ In a recent metaanalysis of six studies, the use of CPAP in surgical patients with OSA demonstrated lower postoperative $\mathrm{AHI}$ and a trend toward shorter length of stay. ${ }^{31}$ Following a functional algorithm could help to guide the screening and management of obese patients with OSA. ${ }^{32}$

\section{Patient selection for ambulatory surgery}

In 2006 and 2014, the ASA published guidelines on the perioperative management of OSA patients, ${ }^{9,10}$ based on the severity of sleep apnea, invasiveness of surgery, type of anesthesia, and the need for postoperative opioids. Based on a systematic review of recent evidence, SAMBA has recommended a consensus statement on the preoperative selection of patients with OSA for ambulatory surgery. ${ }^{11}$ It recommends the STOP-Bang questionnaire as a screening tool.
According to SAMBA guidelines, patients with a diagnosis of OSA and compliant with continuous PAP (CPAP), with optimized comorbid conditions and minimal postoperative opioid requirements, can be considered for ambulatory surgery (Figure 1). However, patients who are noncompliant with CPAP may not be appropriate for ambulatory surgery. At the same time, patients with a presumed diagnosis of OSA based on the screening tool and optimized comorbid conditions may be considered for ambulatory surgery, if postoperative pain relief can be managed predominantly with nonopioid analgesic techniques. In contrast to the ASA OSA guidelines, laparoscopic upper-abdominal surgeries like gastric banding may be safely performed on a day-surgery basis provided perioperative precautions are followed. Because of limited evidence, no guidance was provided for OSA patients undergoing upper-airway surgery. A recent systematic review on obese patient selection for ambulatory surgery showed that the literature lacks enough information to make recommendations regarding the selection of obese patients for ambulatory surgery. ${ }^{33}$ Superobese patients with body mass index (BMI) $>50 \mathrm{~kg} / \mathrm{m}^{2}$ are at increased risk for perioperative complications, while patients with lower BMI do not present any increased risk as long as comorbidities are optimized before surgery. ${ }^{33}$

\section{Outcome of OSA patients undergoing ambulatory surgery}

Recent outcome studies on inpatient surgeries have clearly shown serious cardiac and pulmonary complications in OSA patients, ${ }^{34-36}$ but evidence is limited regarding postoperative outcome in OSA patients undergoing ambulatory surgery. A systematic review by SAMBA evaluated five prospective and two retrospective studies with various ambulatory surgical procedures, including general surgery, ${ }^{8}$ orthopedic surgery, ${ }^{37}$ laparoscopic bariatric surgery, ${ }^{38,39}$ and upperairway surgery. ${ }^{40,41}$ In this review, the postoperative outcomes of 1,491 OSA patients and 2,036 low-risk OSA patients were compared with 2,095 non-OSA patients. ${ }^{11}$ None of these included studies reported any clinically significant adverse outcomes, such as the need for a surgical airway, hypoxic brain injury, longer discharge time, unanticipated hospital admission, or death. Also, the systematic review showed that OSA patients had higher incidence of postoperative hypoxemia, but there was no variation in the need for ventilatory assistance or reintubation. ${ }^{11}$ In a prospective cohort study, those patients with greater possibility for OSA had more attempts of laryngoscopy, difficult laryngoscopic grade, and fiber-optic intubation. ${ }^{8}$ Also, the use of intraop- 


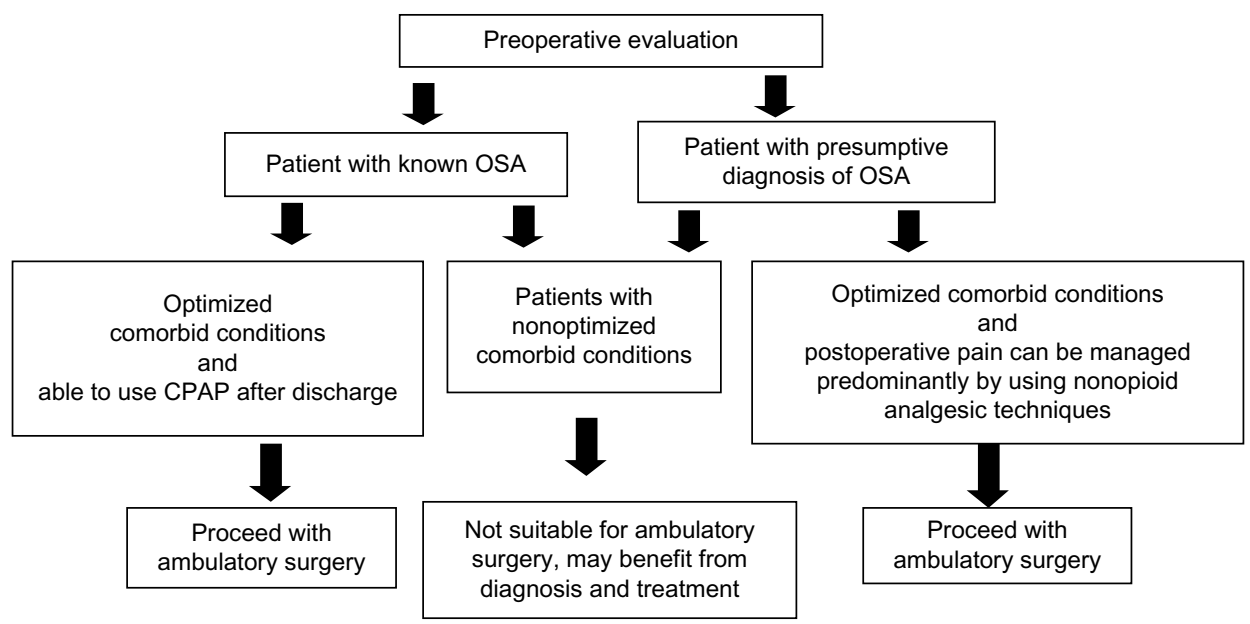

Figure I Decision making in preoperative selection of a patient with obstructive sleep apnea (OSA) for ambulatory surgery.

Notes: Adapted from Joshi GP, Ankichetty SP, Gan TJ, Chung F. Society for Ambulatory Anesthesia consensus statement on preoperative selection of adult patients with obstructive sleep apnea scheduled for ambulatory surgery. Anesth Analg. 20 I2; I 5: 1060-1068. " Promotional and commercial use of the material in print, digital or mobile device format is prohibited without the permission from the publisher Wolters Kluwer Health. Please contact healthpermissions@wolterskluwer.com for further information."

Abbreviation: CPAP, continuous positive airway pressure.

erative ephedrine, metoprolol, and labetalol was greater in OSA patients, but there was no difference in unanticipated hospital admission. ${ }^{8}$ A recent study on 404 ambulatory head and neck procedures in OSA patients showed neither complication nor readmission. ${ }^{42} \mathrm{~A}$ historical cohort study on 77,809 ambulatory surgical procedures did not identify any clinically significant increased rate of unplanned admission related to a prior diagnosis of 674 OSA patients. ${ }^{43}$ The lack of increased postoperative complications in these studies may have been due to careful selection of OSA patients for ambulatory surgery, use of CPAP, and minimal opioids.

The benefits of CPAP in surgical patients have been shown in a recent meta-analysis. ${ }^{31} \mathrm{~A}$ diagnosis of OSA and the use of CPAP therapy were related to a reduction in postoperative complications, especially cardiac arrest and shock. ${ }^{44}$ Another recent study of 2,000 OSA patients in 50 US hospitals found that OSA patients with CPAP treatment had fewer cardiorespiratory complications than OSA patients without CPAP therapy ${ }^{45}$ All these findings confirm the view that patients with OSA may safely undergo ambulatory surgery if they are selected cautiously and receive focused perioperative care.

\section{Perioperative management of OSA patients for ambulatory surgery}

General anesthesia in patients with OSA is challenging, as the administration of anesthetics, sedatives, and analgesics can further deteriorate pharyngeal obstruction in a preexisting airway dysfunction. Perioperatively, various approaches can be used to mitigate the risks and adverse outcomes in OSA patients (Table 2). Since obesity is the major risk factor for OSA, anesthetic management needs to address issues related to obesity as well as OSA. The incidence of difficult intubation and difficult mask ventilation is high in the obese compared to the nonobese population. The presence of OSA is associated with difficult mask ventilation, ${ }^{46}$ as well as eight times more chance of difficult intubation. ${ }^{47} \mathrm{~A}$ neck circumference more than $43 \mathrm{~cm}$ has been shown to have an increased risk of difficult intubation. ${ }^{48}$ However, there is contradictory evidence regarding the predictors of difficult intubation, like severity of OSA, neck circumference, pretracheal soft-tissue thickness, and BMI ${ }^{49} \mathrm{~A}$ Mallampati score of 3 or 4 and male sex may be associated with difficult intubation. ${ }^{50}$ Neck circumference to thyromental distance ratio can predict difficult intubation in obese patients. ${ }^{51} \mathrm{~A}$ recent study has shown that a STOP-Bang score $\geq 3$ predicts difficult intubation. ${ }^{52}$ Obesity was identified as an independent predictor of failed use of a laryngeal mask airway requiring endotracheal intubation. ${ }^{53}$

Adequately skilled help and equipment, including choice of airway aids, should be available before induction of anesthesia. Anesthesia team members should be familiar with a specific difficult airway algorithm, such as the ASA Difficult Airway Guideline. ${ }^{54}$ The head-elevated laryngoscopy position using specific positioning pillows could facilitate direct laryngoscopy. Preoxygenation with continuous application of $10 \mathrm{~cm} \mathrm{H}_{2} \mathrm{O}$ PAP for $3-5$ minutes with a $25^{\circ}$ head-up tilt has been shown to increase the end-tidal concentrations of oxygen..$^{55}$ In morbidly obese patients with a difficult airway, video laryngoscopic intubation with the GlideScope, Storz V-Mac, or McGrath has a better success rate. ${ }^{56}$ The use of awake video laryngoscopy-assisted tracheal intubation has been shown as an alternate method to flexible bronchoscopic intubation. ${ }^{57}$ 
Table 2 Perioperative precautions and risk mitigation for OSA patients

\begin{tabular}{ll}
\hline Anesthetic concern & Principles of management \\
\hline Premedication & Avoid sedating premedication \\
Potential difficult airway (difficult mask ventilation and & Consider $\alpha_{2}$-adrenergic agonists (clonidine, dexmedetomidine) \\
tracheal intubation) & Optimal positioning (head-elevated laryngoscopy position) if patient obese \\
& Adequate preoxygenation \\
& Consider CPAP preoxygenation \\
& Two-handed triple airway maneuvers \\
Gastroesophageal reflux disease & Anticipate difficult airway; personnel familiar with a specific difficult airway algorithm \\
& Consider proton-pump inhibitors, antacids, rapid-sequence induction with cricoid \\
Opioid-related respiratory depression & pressure \\
& Minimize opioid use \\
& Use of short-acting agents (remifentanil) \\
& Multimodal approach to analgesia (NSAIDs, acetaminophen, tramadol, ketamine, \\
& gabapentin, pregabalin, dexmedetomidine, clonidine, dexamethasone, melatonin) \\
Carryover sedation effects from longer-acting intravenous & Consider local and regional anesthesia where appropriate \\
and volatile anesthetic agents & Use of propofol/remifentanil for maintenance of anesthesia \\
& Use of insoluble potent anesthetic agents (desflurane) \\
Excessive sedation in monitored anesthetic care & Use of regional blocks as a sole anesthetic technique \\
Postextubation airway obstruction & Use of intraoperative capnography for monitoring of ventilation \\
& Verify full reversal of neuromuscular blockade \\
& Extubate only when fully conscious and cooperative \\
& Nonsupine posture for extubation and recovery \\
& Resume use of positive airway-pressure device after surgery
\end{tabular}

Note: Adapted from: Seet E, Chung F. Management of sleep apnea in adults - functional algorithms for the perioperative period: Continuing Professional Development. Can J Anaesth. 2010; 57:849. ${ }^{32}$

Abbreviations: OSA, obstructive sleep apnea; CPAP, continuous positive airway pressure; NSAIDs, nonsteroidal anti-inflammatory drugs.

\section{Discharge from PACU for patients with obstructive sleep apnea}

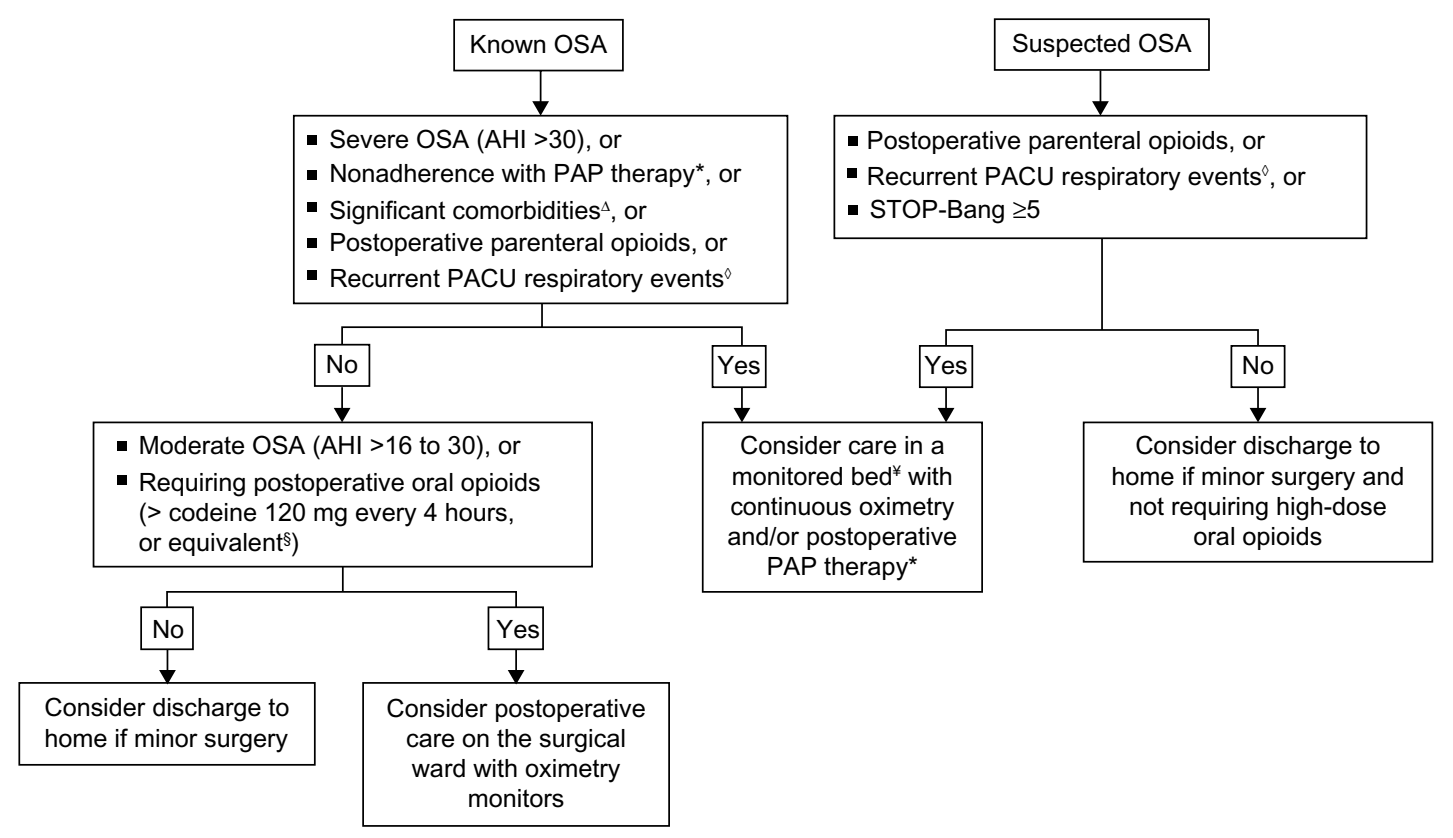

Figure 2 Postoperative management of the diagnosed or suspected OSA patient after general anesthesia.

Notes: Postoperative PACU discharge timing and location for the patient with known or suspected OSA after general anesthesia. Such patients should be monitored for $>60$ minutes after usual PACU criteria are met. *Positive airway pressure (PAP) therapy, including continuous PAP, bilevel PAP, or automatically adjusting PAP; ${ }^{\star}$ significant comorbidities (eg, heart failure, arrhythmias, uncontrolled hypertension, cerebrovascular disease, metabolic syndrome, BMI $>35 \mathrm{~kg} / \mathrm{m}^{2}$ ); ${ }^{0} \mathrm{recurrent}$ postanesthesia care unit (PACU) respiratory event: repeated occurrence of oxygen saturation $<90$ percent, or bradypnea $<8$ breaths/min, or apnea $\geq 10$ seconds, or pain sedation mismatch (high pain and sedation scores concurrently), ${ }^{75}$ sequianalgesic doses of oral opioids: codeine $120 \mathrm{mg}$ every 4 hours, oxycodone 10 mg every 4 hours, hydromorphone 4 mg every 4 hours; ${ }^{*}$ monitored bed: environment with continuous oximetry and the possibility of early medical intervention (eg, intensive care unit, step-down unit, or remote pulse oximetry with telemetry in surgical ward). Adapted from: Seet E, Chung F. Management of sleep apnea in adults - functional algorithms for the perioperative period: Continuing Professional Development. Can J Anaesth. 2010; 57:849.32

Abbreviations: PACU, postanesthesia care unit; OSA, obstructive sleep apnea; AHI, apnea-hypopnea index; PAP, positive airway pressure. 
Gastroesophageal reflux disease due to hypotonia of the lower esophageal sphincter is common in patients with OSA. ${ }^{58}$ Measures should be taken to reduce the risk of gastric acid aspiration by using preoperative proton-pump inhibitors, antacids, and rapid-sequence induction with cricoid pressure. Patients with OSA have an increased sensitivity to the respiratory depressant effects of general anesthetic agents, due to their increased vulnerability for airway collapse, chronic sleep deprivation, and blunted response to hypoxia and hypercarbia. Nocturnal hypoxemia in OSA patients is associated with an increased sensitivity to opioid analgesia. ${ }^{59}$ At the same time, nocturnal desaturation may be associated with increased pain in patients with sleep-disordered breathing. ${ }^{60}$ Pulmonary hypertension is a known complication of long-standing OSA. Intraoperative triggers for increase in pulmonary artery pressures, namely hypoxemia, hypercarbia, hypothermia, and acidosis, should be avoided.

Induction of anesthesia increases atelectasis from $1 \%$ to $11 \%$ of total lung volume in patients with morbid obesity. ${ }^{61}$ Recruitment maneuvers like positive end-expiratory pressure (PEEP) and Valsalva can reduce these effects. Preoxygenation with noninvasive pressure-support ventilation and PEEP with intraoperative recruitment maneuver $\left(40 \mathrm{~cm} \mathrm{H}_{2} \mathrm{O}\right.$ for 40 seconds) increases arterial oxygenation and end-expiratory lung volume. ${ }^{62}$ A recent meta-analysis showed that the recruitment maneuver added to PEEP compared with using PEEP alone increased intraoperative oxygenation and lung compliance. ${ }^{63}$

Short-acting anesthetic agents like propofol, desflurane, and remifentanil are preferred to long-acting agents. General anesthesia with intermediate-acting neuromuscular blocking agents was associated with more risk of respiratory adverse events. ${ }^{64}$ Even a minimal level of residual neuromuscular blockade can cause an increase in postoperative morbidity, due to aspiration, airway obstruction, hypoxia, hypoventilation, and reintubation. ${ }^{65}$ OSA patients should be extubated only when awake, obeying commands, and after confirming adequate airway patency. The Difficult Airway Society has published guidelines for the management of tracheal extubation using a systematic approach. ${ }^{66}$ Patients with obesity and OSA are classified into a category of extubation "at risk" of major complications.

Intraoperative usage of opioid-sparing medications like paracetamol, nonsteroidal anti-inflammatory drugs, COX-2 inhibitors, tramadol, pregabalin, and gabapentin may decrease postoperative opioid requirements. Sedation for surgical procedures under monitored care anesthesia should be monitored with capnography to confirm the adequacy of ventilation. Patients using PAP therapy for OSA at home can use their PAP devices during surgery under mild-tomoderate sedation. ${ }^{67}$ For procedures requiring deep sedation, a secured airway is preferred to an unprotected one. ${ }^{10}$ With regard to childhood OSA and the indication for polysomnography before tonsillectomy, clinical practice guidelines have been published. ${ }^{68-71}$ Recently, a patient-safety tool kit specifically designed for OSA patients undergoing ambulatory surgery was published. It is a single-page guideline incorporating the key elements of patient selection, intraoperative management, and postoperative issues. ${ }^{72}$

\section{Regional anesthesia}

Regional anesthesia in OSA patients provides definite advantages, which allow minimal manipulation of the airway, avoidance of anesthetic drugs with cardiopulmonary depression, reduced perioperative opioid requirements, and reduced postoperative nausea and vomiting. The rate of block failure is directly proportional with a higher BMI. However, the use of ultrasound-guided regional anesthesia in the obese population has led to improved success rates. ${ }^{73}$ Ultrasound-guided neuraxial anesthesia is a viable option to increase the success rate of spinal and epidural anesthesia in obese patients. For shoulder surgery, interscalene block in patients with OSA needs a careful evaluation. Phrenic nerve blockade may be reduced by using ultrasound, a small volume of local anesthetic, and a catheter technique for titrating the dose. A recent technique of superior trunk block, an improvised version of interscalene block that helps to avoid phrenic nerve blockade, is a viable option for OSA patients requiring shoulder surgery. ${ }^{74}$ Patients with OSA undergoing painful ambulatory procedures, such as shoulder repair, foot arthrodesis, anterior cruciate ligament repair, and reconstructive plastic surgeries, may be at higher risk of adverse events, due to a higher requirement of postoperative opioid analgesic.

\section{Postoperative disposition and unplanned admission after ambulatory surgery}

Diagnosed or suspected OSA patients receiving general anesthesia should have extended monitoring for an additional 60 minutes after they have met the modified Aldrete criteria for discharge. ${ }^{32}$ The incidence of recurrent respiratory events in the postanesthesia care unit (PACU) is an indication for continuous postoperative monitoring. ${ }^{75}$ These respiratory events are episodes of apnea $\geq 10$ seconds, (Figure 2) 
bradypnea $<8$ breaths/minute, pain-sedation mismatch, or repeated $\mathrm{O}_{2}$ desaturation $<90 \%$. Repeated occurrence of any of these events is considered recurrent PACU respiratory events. OSA patients with recurrent respiratory events have an increased risk of postoperative respiratory complications. ${ }^{75,76}$ These patients may require postoperative PAP therapy with monitoring. ${ }^{67}$ Ambulatory surgical centers that handle OSA patients should have the backup to manage postoperative complications related to OSA and an agreement with an appropriate inpatient facility. The anesthesiologist and surgeon should agree on postoperative analgesic medication, and patients should be advised to use acetaminophen, nonsteroidal anti-inflammatory drugs, and COX-2 inhibitors rather than opioids. Patients should be educated to sleep in a semiupright position and to apply their PAP devices when sleeping, even during the daytime.

A PACU order-based approach was described by Swart et al to facilitate postoperative decision making for OSA patients. The orders help anesthesiologists to consider the factors related to higher risk of complications in OSA patients, diagnostic follow-up, and possible sleep-medicine consultation..$^{77}$ A recent study showed that if OSA patients were managed with the OSA risk-management protocol, there was no significant increase in postoperative complications. ${ }^{78}$ In the postoperative period, disturbances in sleep architecture were greatest on postoperative night 1 , the night of surgery, and breathing disturbances during sleep were highest on postoperative night $3 .{ }^{17} \mathrm{An}$ increase in postoperative AHI was positively associated with preoperative AHI, male sex, and 72-hour opioid dose. ${ }^{79}$ It is necessary to educate surgeons, patients, and their family regarding the need for increased vigilance after discharge home.

\section{Conclusion}

OSA patients are a special population, and their anesthetic management is challenging, due to difficult airway, sensitivity to general anesthetics, and postoperative pain management. In recent years, there has been better understanding about the effect of anesthetics on postoperative sleep architecture in OSA patients. This warrants careful selection of patients for ambulatory surgery with specific protocols, and risk mitigation is imperative to avoid cancellations and complications. Educating patients and the health care team will improve the perioperative outcome. With appropriate screening and algorithm-based management, the majority of the ambulatory surgical procedure may be done safely in patients with OSA.

\section{Disclosure}

The authors report no conflicts of interest in this work.

\section{References}

1. Isono S. Obstructive sleep apnea of obese adults: pathophysiology and perioperative airway management. Anesthesiology. 2009;110:908-921.

2. Peppard PE, Young T, Barnet JH, Palta M, Hagen EW, Hla KM. Increased prevalence of sleep-disordered breathing in adults. Am J Epidemiol. 2013;177:1006-1014.

3. Young T, Palta M, Dempsey J, Skatrud J, Weber S, Badr S. The occurrence of sleep-disordered breathing among middle-aged adults. $N E n g l$ J Med. 1993;328:1230-1235.

4. Bixler EO, Vgontzas AN, Ten Have T, Tyson K, Kales A. Effects of age on sleep apnea in men. I. Prevalence and severity. Am J Respir Crit Care Med. 1998;157:144-148.

5. Bixler EO, Vgontzas AN, Lin HM, et al. Prevalence of sleep-disordered breathing in women: effects of gender. Am J Respir Crit Care Med. 2001;163:608-613.

6. Singh M, Liao P, Kobah S, Wijeysundera DN, Shapiro C, Chung F. Proportion of surgical patients with undiagnosed obstructive sleep apnoea. Br J Anaesth. 2013;110:629-636.

7. Finkel KJ, Searleman AC, Tymkew H, et al. Prevalence of undiagnosed obstructive sleep apnea among adult surgical patients in an academic medical center. Sleep Med. 2009;10:753-758.

8. Stierer TL, Wright C, George A, Thompson RE, Wu CL, Collop N. Risk assessment of obstructive sleep apnea in a population of patients undergoing ambulatory surgery. J Clin Sleep Med. 2010;6:467-472.

9. Gross JB, Bachenberg KL, Benumof JL, et al. Practice guidelines for the perioperative management of patients with obstructive sleep apnea: a report by the American Society of Anesthesiologists Task Force on Perioperative Management of patients with obstructive sleep apnea. Anesthesiology. 2006;106:1081-1093.

10. Gross JB, Apfelbaum JL, Caplan RA, et al. Practice guidelines for the perioperative management of patients with obstructive sleep apnea: an updated report by the American Society of Anesthesiologists Task Force on Perioperative Management of patients with obstructive sleep apnea. Anesthesiology. 2014;120:268-286.

11. Joshi GP, Ankichetty SP, Gan TJ, Chung F. Society for Ambulatory Anesthesia consensus statement on preoperative selection of adult patients with obstructive sleep apnea scheduled for ambulatory surgery. Anesth Analg. 2012;115:1060-1068.

12. Chung F, Elsaid H. Screening for obstructive sleep apnea before surgery: why is it important? Curr Opin Anaesthesiol. 2009;22:405-411.

13. Lopez PP, Stefan B, Schulman CI, Byers PM. Prevalence of sleep apnea in morbidly obese patients who presented for weight loss surgery evaluation: more evidence for routine screening for obstructive sleep apnea before weight loss surgery. Am Surg. 2008;74:834-838.

14. Malhotra A, White DP. Obstructive sleep apnoea. Lancet. 2002;360: 237-245.

15. Khan A, Patel NK, O'Hearn DJ, Khan S. Resistant hypertension and obstructive sleep apnea. Int J Hypertens. 2013;2013:193010.

16. Drager LF, Togeiro SM, Polotsky VY, Lorenzi-Filho G. Obstructive sleep apnea: a cardiometabolic risk in obesity and the metabolic syndrome. J Am Coll Cardiol. 2013;62:569-576.

17. Chung F, Liao P, Yegneswaran B, Shapiro CM, Kang W. Postoperative changes in sleep-disordered breathing and sleep architecture in patients with obstructive sleep apnea. Anesthesiology. 2014;120:287-298.

18. Chau EH, Lam D, Wong J, Mokhlesi B, Chung F. Obesity hypoventilation syndrome: a review of epidemiology, pathophysiology, and perioperative considerations. Anesthesiology. 2012;117:188-205.

19. Iber C, Ancoli-Israel S, Chesson AL Jr, Quan SF. The AASM Manual for the Scoring of Sleep and Associated Events: Rules, Terminology and Technical Specifications. Westchester (IL): American Academy of Sleep Medicine; 2007. 
20. Abrishami A, Khajehdehi A, Chung F. A systematic review of screening questionnaires for obstructive sleep apnea. Can J Anaesth. 2010;57:423-438.

21. Chung F, Yegneswaran B, Liao P, et al. STOP questionnaire: a tool to screen patients for obstructive sleep apnea. Anesthesiology. 2008;108: 812-821.

22. Chung F, Subramanyam R, Liao P, Sasaki E, Shapiro C, Sun Y. High STOP-Bang score indicates a high probability of obstructive sleep apnoea. Br J Anaesth. 2012;108:768-775.

23. Farney RJ, Walker BS, Farney RM, Snow GL, Walker JM. The STOPBang equivalent model and prediction of severity of obstructive sleep apnea: relation to polysomnographic measurements of the apnea/ hypopnea index. J Clin Sleep Med. 2011;7:459-465.

24. Ramachandran SK, Josephs LA. A meta-analysis of clinical screening tests for obstructive sleep apnea. Anesthesiology. 2009;110:928-939.

25. Chung F, Chau E, Yang Y, Liao P, Hall R, Mokhlesi B. Serum bicarbonate level improves specificity of STOP-bang screening for obstructive sleep apnea. Chest. 2013;143:1284-1293.

26. Chung F, Yang Y, Liao P. Predictive performance of the STOP-Bang score for identifying obstructive sleep apnea in obese patients. Obes Surg. 2013;23:2050-2057.

27. Vasu TS, Doghramji K, Cavallazzi R, et al. Obstructive sleep apnea syndrome and postoperative complications: clinical use of the STOPBANG questionnaire. Arch Otolaryngol Head Neck Surg. 2010;136: 1020-1024.

28. Chung F, Liao P, Elsaid H, Islam S, Shapiro CM, Sun Y. Oxygen desaturation index from nocturnal oximetry: a sensitive and specific tool to detect sleep-disordered breathing in surgical patients. Anesth Analg. 2012;114:993-1000.

29. Chung F, Zhou L, Liao P. Parameters from preoperative overnight oximetry predict postoperative adverse events. Minerva Anestesiol. 2014;80:1084-1095.

30. Liao P, Yegneswaran B, Vairavanathan S, Zilberman P, Chung F. Postoperative complications in patients with obstructive sleep apnea: a retrospective matched cohort study. Can J Anaesth. 2009;56:819-828.

31. Nagappa M, Mokhlesi B, Wong J, Wong DT, Kaw R, Chung F. The effects of continuous positive airway pressure on postoperative outcomes in obstructive sleep apnea patients undergoing surgery: a systematic review and meta-analysis. Anesth Analg. 2015;120:1013-1023.

32. Seet E, Chung F. Management of sleep apnea in adults - functional algorithms for the perioperative period: Continuing Professional development. Can J Anaesth. 2010;57:849-864.

33. Joshi GP, Ahmad S, Riad W, Eckert S, Chung F. Selection of obese patients undergoing ambulatory surgery: a systematic review of the literature. Anesth Analg. 2013;117:1082-1091.

34. Kaw R, Chung F, Pasupuleti V, Mehta J, Gay PC, Hernandez AV. Meta-analysis of the association between obstructive sleep apnoea and postoperative outcome. Br J Anaesth. 2012;109:897-906.

35. Mokhlesi B, Hovda MD, Vekhter B, Arora VM, Chung F, Meltzer DO Sleep-disordered breathing and postoperative outcomes after elective surgery: analysis of the nationwide inpatient sample. Chest. 2013;144: 903-914.

36. Memtsoudis SG, Stundner O, Rasul R, et al. The impact of sleep apnea on postoperative utilization of resources and adverse outcomes. Anesth Analg. 2014;118:407-418.

37. Liu S, Chisholm M, John R, Ngeow J, Ma Y, Memtsoudis S. Risk of postoperative hypoxemia in ambulatory orthopedic surgery patients with diagnosis of obstructive sleep apnea: a retrospective observational study. Patient Saf Surg. 2010;4:9.

38. Kurrek MM, Cobourn C, Wojtasik Z, Kiss A, Dain SL. Morbidity in patients with or at high risk for obstructive sleep apnea after ambulatory laparoscopic gastric banding. Obes Surg. 2011;21:1494-1498.

39. Watkins BM, Montgomery KF, Ahroni JH, Erlitz MD, Abrams RE, Scurlock JE. Adjustable gastric banding in an ambulatory surgery center. Obes Surg. 2005;15:1045-1049.

40. Hathaway B, Johnson JT. Safety of uvulopalatopharyngoplasty as outpatient surgery. Otolaryngol Head Neck Surg. 2006;134:542-544.
41. Kieff DA, Busaba NY. Same-day discharge for selected patients undergoing combined nasal and palatal surgery for obstructive sleep apnea. Ann Otol Rhinol Laryngol. 2004;113:128-131.

42. Baugh R, Burke B, Fink B, Garcia R, Kominsky A, Yaremchuk K. Safety of outpatient surgery for obstructive sleep apnea. Otolaryngol Head Neck Surg. 2013;148:867-872.

43. Bryson GL, Gomez CP, Jee RM, Blackburn J, Taljaard M, Forster AJ. Unplanned admission after day surgery: a historical cohort study in patients with obstructive sleep apnea. Can J Anaesth. 2012;59:842-851.

44. Mutter TC, Chateau D, Moffatt M, Ramsey C, Roos LL, Kryger M. A matched cohort study of postoperative outcomes in obstructive sleep apnea: could preoperative diagnosis and treatment prevent complications? Anesthesiology. 2014;121:707-718.

45. AbdelsattarZM, Hendren S, Wong SL, Campbell DA Jr, Ramachandran SK. The impact of untreated obstructive sleep apnea on cardiopulmonary complications in general and vascular surgery: a cohort study. Sleep. Epub 2015 Feb 18.

46. Kheterpal S, Martin L, Shanks AM, Tremper KK. Prediction and outcomes of impossible mask ventilation: a review of 50,000 anesthetics. Anesthesiology. 2009;110:891-997.

47. Siyam MA, Benhamou D. Difficult endotracheal intubation in patients with sleep apnea syndrome. Anesth Analg. 2002;95:1098-1102.

48. Gonzalez H, Minville V, Delanoue K, Mazerolles M, Concina D, Fourcade $\mathrm{O}$. The importance of increased neck circumference to intubation difficulties in obese patients. Anesth Analg. 2008;106:1132-1136.

49. Murphy C, Wong DT. Airway management and oxygenation in obese patients. Can J Anaesth. 2013;60:929-945.

50. Neligan PJ, Porter S, Max B, Malhotra G, Greenblatt EP, Ochroch EA. Obstructive sleep apnea is not a risk factor for difficult intubation in morbidly obese patients. Anesth Analg. 2009;109:1182-1186.

51. Kim WH, Ahn HJ, Lee CJ, et al. Neck circumference to thyromental distance ratio: a new predictor of difficult intubation in obese patients. Br J Anaesth. 2011;106:743-748.

52. Acar HV, Uysal HY, Kaya A, Ceyhan A, Dikmen B. Does the STOPBang, an obstructive sleep apnea screening tool, predict difficult intubation? Eur Rev Med Pharmacol Sci. 2014;18:1869-1874.

53. Ramachandran SK, Mathis MR, Tremper KK, Shanks AM, Kheterpal S. Predictors and clinical outcomes from failed Laryngeal Mask Airway Unique: a study of 15,795 patients. Anesthesiology. 2012;116: $1217-1226$

54. Apfelbaum JL, Hagberg CA, Caplan RA, et al. Practice guidelines for management of the difficult airway: an updated report by the American Society of Anesthesiologists Task Force on Management of the Difficult Airway. Anesthesiology. 2013;118:251-270.

55. Delay JM, Sebbane M, Jung B, et al. The effectiveness of noninvasive positive pressure ventilation to enhance preoxygenation in morbidly obese patients: a randomized controlled study. Anesth Analg. 2008;107: 1707-1713.

56. Maassen R, Lee R, Hermans B, Marcus M, van Zundert A. A comparison of three videolaryngoscopes: the Macintosh laryngoscope blade reduces, but does not replace, routine stylet use for intubation in morbidly obese patients. Anesth Analg. 2009;109:1560-1565.

57. Moore AR, Schricker T, Court O. Awake videolaryngoscopy-assisted tracheal intubation of the morbidly obese. Anaesthesia. 2012;67:232-235.

58. Sabate JM, Jouet P, Merrouche M, et al. Gastroesophageal reflux in patients with morbid obesity: a role of obstructive sleep apnea syndrome? Obes Surg. 2008;18:1479-1484.

59. Doufas AG, Tian L, Padrez KA, et al. Experimental pain and opioid analgesia in volunteers at high risk for obstructive sleep apnea. PLoS One. 2013;8:e54807.

60. Doufas AG, Tian L, Davies MF, Warby SC. Nocturnal intermittent hypoxia is independently associated with pain in subjects suffering from sleep-disordered breathing. Anesthesiology. 2013;119:1149-1162.

61. Reinius H, Jonsson L, Gustafsson S, et al. Prevention of atelectasis in morbidly obese patients during general anesthesia and paralysis: a computerized tomography study. Anesthesiology. 2009;111: 979-987. 
62. Futier E, Constantin JM, Pelosi P, et al. Noninvasive ventilation and alveolar recruitment maneuver improve respiratory function during and after intubation of morbidly obese patients: a randomized controlled study. Anesthesiology. 2011;114:1354-1363.

63. Aldenkortt M, Lysakowski C, Elia N, Brochard L, Tramèr MR. Ventilation strategies in obese patients undergoing surgery: a quantitative systematic review and meta-analysis. Br J Anaesth. 2012;109: 493-502.

64. Grosse-Sundrup M, Henneman JP, Sandberg WS, et al. Intermediate acting non-depolarizing neuromuscular blocking agents and risk of postoperative respiratory complications: prospective propensity score matched cohort study. BMJ. 2012;345:e6329.

65. Murphy GS, Brull SJ. Residual neuromuscular block: lessons unlearned. Part I: definitions, incidence, and adverse physiologic effects of residual neuromuscular block. Anesth Analg. 2010;111:120-128.

66. Popat M, Mitchell V, Dravid R, Patel A, Swampillai C, Higgs A. Difficult Airway Society Guidelines for the management of tracheal extubation. Anaesthesia. 2012;67:318-340.

67. Sundar E, Chang J, Smetana GW. Perioperative screening for and management of patients with obstructive sleep apnea. J Clin Outcomes Manag. 2011;18:399-411.

68. Marcus CL, Brooks LJ, Draper KA, et al. Diagnosis and management of childhood obstructive sleep apnea syndrome. Pediatrics. 2012;130: 576-584.

69. Roland PS, Rosenfeld RM, Brooks LJ, et al. Clinical practice guideline: polysomnography for sleep-disordered breathing prior to tonsillectomy in children. Otolaryngol Head Neck Surg. 2011;145:S1-S15.

70. Baugh RF, Archer SM, Mitchell RB, et al. Clinical practice guideline: tonsillectomy in children. Otolaryngol Head Neck Surg. 2011;144: S1-S30.

71. Subramanyam R, Varughese A, Willging JP, Sadhasivam S. Future of pediatric tonsillectomy and perioperative outcomes. Int J Pediatr Otorhinolaryngol. 2013;77:194-199.
72. Accreditation Association for Ambulatory Health Care. Patient Safety Toolkit: Ambulatory Surgery and Obstructive Sleep Apnea. Skokie (IL): AAAHC; 2012. Available from: https://www.aaahc.org/Documents/ Institute/aaahc_workmat_11-8-12\%20pdf.pdf. Accessed August 12, 2015.

73. Schwemmer U, Papenfuss T, Greim C, Brederlau J, Roewer N. Ultrasound-guided interscalene brachial plexus anaesthesia: differences in success between patients of normal and excessive weight. Ultraschall Med. 2006;27:245-250.

74. Burckett-St Laurent D, Chan V, Chin KJ. Refining the ultrasound-guided interscalene brachial plexus block: the superior trunk approach. Can J Anaesth. 2014;61:1098-1102.

75. Gali B, Whalen FX, Schroeder DR, Gay PC, Plevak DJ. Identification of patients at risk for postoperative respiratory complications using a preoperative obstructive sleep apnea screening tool and postanesthesia care assessment. Anesthesiology. 2009;110:869-877.

76. Orlov D, Ankichetty S, Chung F, Brull R. Cardiorespiratory complications of neuraxial opioids in patients with obstructive sleep apnea: a systematic review. J Clin Anesth. 2013;25:591-599.

77. Swart P, Chung F, Fleetham J. An order-based approach to facilitate postoperative decision-making for patients with sleep apnea. Can J Anaesth. 2013;60:321-324.

78. Chong CT, Tey J, Leow SL, et al. Management plan to reduce risks in perioperative care of patients with obstructive sleep apnoea averts the need for presurgical polysomnography. Ann Acad Med Singapore. 2013;42:110-119.

79. Chung F, Liao P, Elsaid H, Shapiro CM, Kang W. Factors associated with postoperative exacerbation of sleep-disordered breathing. Anesthesiology. 2014;120:299-311.
Ambulatory Anesthesia

\section{Publish your work in this journal}

Ambulatory Anesthesia is an international, peer reviewed, open access journal publishing articles that address all aspects of ambulatory anesthesia practice, in particular: anesthetic techniques, sedation and safety practices, pharmacokinetics, preoperative evaluation, analgesia interventions, regulatory and compliance issues, postoperative recovery,

\section{Dovepress}

patient satisfaction, administrative topics, and cost analysis themes. The manuscript management system is completely online and includes a very quick and fair peer review system, which is all easy to use. Visit http://www.dovepress.com/testimonials.php to read real quotes from published authors. 